\title{
A produção simbólica dos desastres naturais: composições, seleções e recortes ${ }^{1}$
}

Victor Marchezini*

\section{Resumo}

Desastres podem ser compreendidos como processos em que subjaz uma produção simbólica sempre construída por agentes em disputa pelo monopólio da visão oficial. Palavras e imagens são usadas pelos agentes para enunciar o que se constitui como ordem e desordem, para conformar uma dada visão sobre o desastre, definindo uma seleção do tempo real e o que vem a se constituir como a realidade. 0 objetivo deste artigo é analisar esse processo de produção simbólica do desastre a partir de uma seleção de reportagens e imagens dos saques ocorridos durante as inundações e deslizamentos na região do Vale do Itajaí/SC em novembro de 2008.

\section{Palavras-chave}

Poder simbólico. Mídia. Desastres.

\begin{abstract}
Disasters can be comprehended as processes that were defined by the symbolic production, which it constituted by the agents in competition for the monopoly of official vision. Words and images are used by agents to enunciate what consists order and disorder, to frame one vision about the disaster, defining the selection of real time and, as a result, what it can be considered as reality. This paper aims to analyze the process of symbolic production of the disaster, from the selection of notices and images about the looting occurred during floods and landslides in the region of Itajai Valley/SC in November 2008.
\end{abstract}

\section{Keywords}

Symbolic power. Media. Disasters.

\footnotetext{
${ }^{1}$ Apoio: Fapesp.

* Doutor em Sociologia pela Universidade Federal de São Carlos (UFSC) e especialista em Direitos Humanos, Gestão de Riscos e Políticas Públicas de Prevenção a Desastres pela Fundação Henry Dunant. E-mail: victor.marchezini@gmail.com .
} 


\section{Introdução}

Os estudos científicos acerca dos "desastres naturais" têm início nas primeiras décadas do século XX, mas somente a partir de 1970, quando passam a ser analisados pelas Ciências Sociais, que se problematiza a natureza desses, compreendendo-os como resultado das relações sociais, ou seja, considerase que para a configuração de um desastre não se depende somente de uma ameaça natural, mas sim de uma dada organização social. O resultado dessa interação entre uma ameaça natural e uma dada organização poderia configurar um desastre, dependendo do reconhecimento público da vivência de uma crise, espacializada a partir de uma quantidade de danos ambientais, materiais e humanos ocorridos num dado tempo e lugar.

Este artigo tem por objetivo analisar sociologicamente a produção simbólica daquilo que é entendido como desastre, focando-se em algumas relações de poder subjacentes que tendem a impor o que é considerado como ordem e desordem nesse contexto. Para tanto, irá se debruçar sobre a análise dos desastres relacionados às chuvas, os quais têm sido classificados como "desastres naturais", como uma função prática cujo objetivo é não problematizá-los como um fenômeno também social.

\section{A produção simbólica das chuvas atípicas}

Bourdieu (2004) elaborou o conceito de poder simbólico para se referir ao poder de constituir o dado pela enunciação, como um poder capaz de fazer ver e fazer crer, destinado a confirmar ou transformar a visão de mundo e, consequentemente, a ação sobre esse mundo e o próprio mundo. Como um poder quase mágico, ele traria a possibilidade de adquirir aquilo que muitas vezes é obtido pela força física e/ou econômica, em razão de gerar um efeito de mobilização que só se efetiva pelo fato de ser ignorado como arbitrário. Assim, ele se exerceria e se definiria numa relação entre os que o executam e aqueles que estão sujeitos a ele. Pelo fato de ser ignorado como arbitrário, esse "poder simbólico é [...] poder invisível o qual só pode ser exercido com a cumplicidade daqueles que não querem saber que lhe estão sujeitos ou mesmo que o exercem" (BOURDIEU, 2004, p. 7-8). Seria, desse modo, um poder constituído a partir da relação, pois, se o real é relacional, o poder simbólico é um poder de construção da realidade. 
Nesse sentido, o que faria do poder das palavras e das palavras de ordem um poder de manter a ordem ou de subvertê-la seria a crença na legitimidade das palavras daquele que as pronuncia e não da competência das palavras, pois o poder simbólico "é uma forma transformada, quer dizer, irreconhecível, transfigurada e legitimada, das outras formas de poder" (Idem, p. 15), principalmente, mas não somente, do poder econômico. Isto é, "o poder das palavras não reside nas próprias palavras, mas nas condições que dão poder às palavras criando a crença coletiva" (BOURDIEU, 2006, p. 162). A realidade construída a partir de palavras seria assim fruto de relações de poder entre os agentes cujas disputas engendrariam campos (campo do esporte, artístico etc.), construídos a partir das relações dinâmicas. Desse modo, haveria um campo de produção simbólica, definido como "um microcosmos da luta simbólica entre as classes" de agentes constituídas a partir da relação. Tais agentes lutam "pela produção do senso comum ou, mais precisamente, pelo monopólio da nomeação legítima como imposição oficial - isto é, explícita e pública - da visão legítima do mundo social”. Em razão disso, "investem o capital simbólico que adquiriram nas lutas anteriores e sobretudo todo o poder que detêm sobre as taxinomias instituídas, como os títulos" (BOURDIEU, 2004, p. 146), os quais poderiam ser vislumbrados, por exemplo, a partir dos títulos de especialistas, de peritos, de experts, tal como os meteorologistas, os engenheiros civis, os agentes de defesa civil, os geólogos, os próprios sociólogos etc.

Assim, muito do que está dado, o que está inscrito ao mesmo tempo nas coisas e nos cérebros, e que se apresenta com as aparências da evidência, que passa despercebido porque considerado perfeitamente natural, seria fruto de uma afirmação com autoridade e considerado uma verdade com força de lei. O poder simbólico aí instaurado é capaz de produzir a existência daquilo que enuncia, pois as coisas ditas com autoridade, isto é, à vista de todos e em nome de todos, de forma pública e oficial, são sancionadas, santificadas e consagradas, fazendo-as existir como dignas de existir, como conforme à natureza das coisas, naturais. Entretanto, salienta Bourdieu (2004, p. 115) que “as classificações mais 'naturais' apoiam-se em características que nada têm de natural e que são (...) produto de uma imposição arbitrária, quer dizer, de um estado anterior da relação de forças no campo das lutas pela delimitação legítima”. Pois as classificações práticas, como definidoras da realidade social, estão sempre subordinadas a funções práticas e orientadas para a produção de efeitos sociais, posto que são engendradas a partir de relações de poder. 
O autor critica o fato de se dar "menos importância aos grandes acontecimentos exteriores e aos acasos da fatalidade, [pois] pensa-se que eles são pouco capazes de revelar alguma coisa de essencial a respeito do objeto considerado" (BOURDIEU, 2004, p. 68). A primeira tarefa da ciência social seria instaurar como "norma fundamental da prática científica a conversão do pensamento, a revolução do olhar, a ruptura com o pré-construído e com tudo o que, na ordem social - e no universo douto - o sustenta” (Idem, p. 49). O objetivo da ciência social seria compreender as lutas pelas classificações, porque o problema da classificação é um problema político, surge na lógica da luta política (BOURDIEU, 1996). Os desastres são classificados como naturais, mas não haveria lógicas assimétricas de poder subsumidas na definição da realidade social que esse conceito encerra? Poderiam os desastres, classificados como naturais, ser submetidos a essa revolução do olhar proposta por Bourdieu?

A linguagem corrente "contém, em seu vocabulário e sintaxe, toda uma filosofia petrificada do social" (BOURDIEU et al., 2007, p. 32) e se instaura a partir de relações. Se o que confere o caráter de relação é o poder que sobre ela está imbuído entre aqueles que tentam impor uma determinada lógica e aqueles que a esta resistem, haveria o poder de constituição de uma linguagem cujo intuito é criar uma realidade. Palavras e conceitos criariam realidades a fim de dar sentido ao mundo social, mas a produção simbólica dessas estaria concernente ao capital possuído pelos agentes na relação que empreendem. Assim, o que é "natural" passaria anteriormente por uma luta classificatória para impor esse caráter a algo que, antes de tudo, é uma construção social. O "natural" traria consigo a neutralidade e imparcialidade, imiscuindo sobre ele a necessidade de deflagrar possíveis relações de poder imbricadas. O "natural" seria "assim mesmo", não havendo necessidade de problematização. As chuvas são classificadas como fenômenos naturais e há uma ciência - ciência atmosférica - que se incumbe de explicar a sua formação, os fatores que influem sobre ela, os tipos de chuvas que ocorrem, os tipos de nuvens, fazendo-se distinções entre o que é considerado clima e o que é admitido como tempo, prognosticando as quantidades de chuvas esperadas para determinadas localidades etc.

Embora esse fenômeno físico seja considerado natural, as ações humanas têm um impacto sobre o clima e sobre o regime de chuvas, sendo as conclusões do Painel Intergovernamental sobre Mudanças Climáticas (IPCC, 2007) uma constatação disso. Segundo Nunes (2009), no que se refere ao sistema climático, as mudanças induzidas pelas ações antrópicas relacionam- 
se "às alterações na composição do ar e no balanço de energia que, devido à dinâmica intrínseca da atmosfera, afetam locais muito além da fonte de origem" (NUNES, 2009, p. 54). Dentre essas ações, estão, por exemplo, o processo de mudança do uso da terra, o desmatamento, a urbanização, que altera "o fluxo de energia e de umidade no nível local ao substituir a vegetação por asfalto e outros materiais, além de modificar o curso dos rios, muitas vezes canalizados, e mudar o fluxo natural das circulações, criando verdadeiros corredores que canalizam os ventos" (NUNES, 2008, p. 73). No Brasil, por exemplo, a seca na região Amazônica no ano de 2005 prova o quanto o regime de chuvas está sendo alterado como decorrência das ações humanas sobre o meio ambiente. Se a seca que se abateu sobre a região Amazônica causou mortes e impactos ambientais, sociais e econômicos, os impactos de uma seca em Israel não serão os mesmos. Isto é, um fenômeno físico tem um determinado impacto conforme o meio social que ele encontra, pois "episódios similares do ponto de vista energético (...) [causam] efeitos distintos, de acordo com as características socioambientais da localidade afetada" (NUNES, 2009, p. 57).

Se pensarmos no caso das chuvas, enquanto estas podem ser consideradas como uma bênção quando atingem determinadas regiões do semiárido nordestino (o ano de 2004, de 2009 e 2010 talvez contestem essa versão), podem significar ameaça quando atingem determinadas cidades brasileiras, ou seja, há diferentes representações leigas e peritas em relação ao fenômeno físico denominado chuvas, como demonstrado por Valencio et al. (2005). Mas essas representações revelam determinadas relações de poder que confluem para processos sociais, inclusive o de produção simbólica do desastre. Assim, quando chuvas caem sobre determinadas cidades brasileiras, elas passam a ser classificadas como "responsáveis" por desastres, sendo estes, em razão disso, nomeados como "desastres naturais" pelos meios de comunicação e por algumas áreas do meio acadêmico.

Dombrowsky (1998) argumenta sobre o fato de a linguagem empregada, muitas vezes pelos meios de comunicação, estruturar percepções em torno do desastre, tendendo a tratar o fenômeno das chuvas como o responsável por este e, portanto, operando uma construção da realidade do mundo social permeada por palavras, pois, quando "(...) se trata do mundo social, as palavras criam as coisas, já que criam o consenso sobre a existência e o sentido das coisas" (BOURDIEU, 1996, p. 127). Nesse sentido, substantivos são "combinados a adjetivos tácitos, os verbos a advérbios silenciosos, que tendem a consagrar ou a condenar, a instituir como digno de existência e 
de perseverar no ser, ou, ao contrário, a destituir, a degradar, a desacreditar" (BOURDIEU, 1988: 16). Assim, palavras e frases do tipo "Chuvas matam mais dois em Minas Gerais", "Chuvas matam mãe e filho soterrados em Pernambuco", "Chuvas castigam o Paraná e o Espírito Santo”, "o temporal também fez estragos na região litorânea", "Chuvas causam alagamentos e falta de energia", estruturariam percepções e representações de modo a dotar as chuvas de um poder sobrenatural, pseudoconcreto, mágico e animista (DOMBROWSKY, 1998), isto é, capaz de punir, de matar, de causar desastres.

Desse modo, opera-se a nominação de um fenômeno físico, no caso as chuvas, como o agente responsável pelo desastre quando, na verdade, o desastre não é causado pelas chuvas. Há uma produção simbólica em torno do fenômeno natural das chuvas, das chuvas atípicas como agentes do desastre e que se difundem pelos meios de comunicação em diversas regiões do Brasil. Em Manaus, após as chuvas de abril de 2007, noticiouse: “Os ministros Márcio Fortes (Ministério das Cidades) e Geddel Vieira Lima (Ministério da Integração) anunciaram ontem, em Manaus, que o governo federal irá liberar $\mathrm{R} \$ 135$ milhões para a reconstrução dos locais que sofreram alagamentos e desabamentos em razão das chuvas atípicas dos últimos dez dias na capital" (AGÊNCIA FOLHA, 2007; grifo nosso); e, como um segundo exemplo ilustrativo, temos o caso de São Luís/MA, em julho de 2008: "as chuvas fortes e atípicas voltaram a castigar São Luís ontem. As precipitações começaram a cair na madrugada e se intensificaram ao meiodia, deixando muitas avenidas alagadas e causando transtornos a motoristas (...) as chuvas atípicas na cidade são justificáveis por dados técnicos. Segundo o meteorologista Márcio Eloi, do Laboratório de Meteorologia do Núcleo Geoambiental da Universidade Estadual do Maranhão (Uema), mesmo atuando com frequência nos meses de junho e julho, as águas são atípicas e impulsionadas por variações de temperaturas" (TV CANAL 13, 2008; grifo nosso).

Embora haja um consenso entre cientistas, sobretudo da área de ciências naturais, de que os eventos extremos relacionados às Mudanças Climáticas aumentarão a intensificação da precipitação pluviométrica em certas porções do planeta, dentre as quais a porção Centro-Sul do Brasil, pode haver uma apropriação discursiva para a produção de uma realidade mais afeita a certos agentes dotados de capital na luta concorrencial travada no campo de produção simbólica em torno da definição da real "natureza” dos desastres. Isto é, se as chuvas atípicas se caracterizam como um mecanismo que tenta dotar 
as chuvas de um poder de destruição, naturalizando-as como responsáveis pelos efeitos causados, as Mudanças Climáticas vêm a fortalecer esse discurso do caráter "natural" da fúria das chuvas como as grandes responsáveis pelos desastres. Nos campos de disputa em torno dessas produções antecipadas das interpretações sobre os riscos, os desastres e as Mudanças Climáticas, há mecanismos para torná-las abstratas, como perigos e ameaças que não são tangíveis, imediatos e visíveis no dia a dia, mas sim como problemas futuros, como projeções e probabilidades que, evidentemente, são objeto de disputa no presente: nos discursos científicos dos céticos e dos catastrofistas que ganham a atenção da mídia; nos discursos políticos entre os estados nacionais que se reúnem nas conferências da ONU sobre o tema; nos negócios econômicos promovidos em torno do mercado de carbono etc. (GIDDENS, 2009). Enquanto os discursos em torno das Mudanças Climáticas ganham visibilidade, de fora dos noticiários estão as pautas invisíveis de desastres cotidianos, de desastres que continuam e de outras catástrofes sociais que se produzem silenciosamente no processo de abandono social dos atingidos em desastres (VALENCIO, SIENA, MARCHEZINI, 2011; MARCHEZINI, 2014a; 2014b).

A produção social do desastre se expressa nos processos de territorialização, mas os enredos da tragédia só ganham visibilidade esporádica na pauta dos noticiários quando as chuvas revelam a crise crônica e evoca-se, como afirma Valencio (2012), um dia do desastre, materializado pontualmente nos danos e perdas ocorridos em inundações e deslizamentos. As chuvas, como fenômeno natural, só revelam a crise crônica, elas não causam os desastres e seus efeitos. O desastre é resultado de uma "interação deletéria entre um evento natural ou tecnológico e a organização social, que coloca em "disrupção" as rotinas de um dado lugar e gera elevados custos (temporais, materiais e psicossociais)" (VALENCIO et al., 2005, p. 163-164). Isto é, a "calamidade é o ápice de um processo construído cotidianamente, especialmente em áreas de registros crônicos ou negligenciadas" (NUNES, 2009, p. 55). Em outros termos, as chuvas são naturais, os desastres são socioambientais.

O rompimento com esse pressuposto recorrente na literatura sobre perigos e desastres, o de que uma vida normal seria interrompida por um fenômeno natural e este seria o agente causador de danos, foi impulsionado, em grande parte, pelas discussões acerca da teoria da sociedade de risco (BECK, 1997; GIDDENS, 1991). A partir dessa abordagem, os riscos sociais, políticos, econômicos são vislumbrados como fruto do desenvolvimento da sociedade moderna. Tais riscos não são mais residuais, mas tendem a escapar 
do controle das instituições, tornando-se centros de conflitos políticos, não só públicos, como privados. O processo de modernização fez com que tais riscos deixassem de ser acidentais, tornando-se parte constitutiva da própria modernidade, decorrentes da incisiva intervenção humana sobre o meio. Entretanto, tanto Giddens (1991) quanto Beck (1997) são criticados por não incorporarem a diversidade social envolvida nos processos discursivos, sociais e políticos de "construção" dos riscos, isto é, não há "nenhuma referência aos distintos modos pelos quais os atores sociais evocam a noção de risco, nem às dinâmicas da acumulação que subordinam as escolhas técnicas, nem tampouco ao trabalho de construção discursiva de que depende a configuração das alianças no âmbito das lutas sociais" (ACSELRAD, 2002, p. 4).

$\mathrm{Na}$ realidade dos municípios brasileiros, a injustiça ambiental e os desastres cotidianos expressam-se na superposição espacial de problemas sociais e ambientais, que explicitam a coexistência dos piores indicadores socioeconômicos com os riscos de inundações e deslizamentos de terra, bem como um ambiente intensamente poluído e serviços sociais (quando os há) extremamente precários. Nessas hiperperiferias se convive com situações de extrema pauperização, péssimas condições sociais e exposição cumulativa a diversos tipos de risco (ALVES; TORRES, 2006). Tais condições de vulnerabilidade e de exposição aos riscos não decorrem de fenômenos naturais, mas sim de processos de vulnerabilização (ACSELRAD, 2006a), ou seja, de processos sociais, históricos e territorialmente circunscritos, cujas práticas econômicas e político-institucionais concorrem para tornar vulneráveis determinados grupos sociais, para vulnerabilizá-los. Dito de outro modo, antes da estação chuvosa já está definido quem será exposto aos riscos socioambientais, a que tipo de riscos estará suscetível e quais os graus de exposição. Os mecanismos de produção dessa desigualdade ambiental, ou seja, da "exposição desproporcional dos socialmente mais desprovidos aos riscos das redes técnico-produtivas da riqueza ou sua despossessão ambiental pela concentração dos benefícios do desenvolvimento em poucas mãos" (ACSELRAD, 2010, p.109), manifestam-se sob a forma de proteção ambiental desigual, como também pelo acesso desigual aos recursos ambientais (ACSELRAD et al., 2008).

Quando a implementação de políticas ambientais e/ou sua omissão diante das forças de mercado gera $(\mathrm{m})$ riscos ambientais desproporcionais aos agentes com menor capital econômico, político etc., pode-se dizer que a proteção ambiental é desigual. Mas essa desigualdade também se expressa no acesso aos recursos ambientais: "os mais ricos tendem a escapar dos riscos 
ambientais residindo em áreas mais protegidas, cujo solo tem mais valor. Aos mais pobres correspondem condições ambientais de existência mais degradadas, por um duplo mecanismo" (ACSELRAD et al., 2008, p. 78). Nesse duplo mecanismo, populações de menor renda são empurradas para áreas de maior risco e com menos infraestrutura, como também as fontes de risco ambiental e de grande impacto ecológico são direcionadas para essas áreas.

Acselrad (2006b) salienta que essas ocupações tendem a ocorrer em áreas desprovidas de interesse e possibilidade de exploração econômica pelo capital imobiliário, como, de modo geral, as encostas, os mananciais e as áreas de proteção ambiental. Carmo (2014) esboça um retrato dessas condições de ocupação em encostas, explicitando a desigualdade ambiental e os graus diferenciados de exposição e segurança humana em contextos de riscos de desastres. A partir da análise de um conjunto de informações do Censo Demográfico 2010, o autor atenta para o número de domicílios particulares situados em aglomerados subnormais ${ }^{2}$ e localizados em áreas com declividade moderada e acentuada ${ }^{3}$. Somente os municípios de Salvador, São Paulo e Rio de Janeiro somam mais de um milhão de domicílios situados em aglomerados subnormais, sendo que mais de 630 mil destes (59,66\% do total) estão em áreas com aclividade/declividade moderada e alta (IBGE, 2013).

Ao operar para a produção simbólica dos "desastres naturais" como uma fatalidade e como algo naturalizado, a organização social e seus problemas históricos (pobreza, desigualdade, falta de equipamentos públicos etc.) passam a ser fatores não problematizados, de modo que a temporalidade do desastre passa a remeter à ocorrência do fenômeno das chuvas e não propriamente ao rearranjo das relações de poder imbricadas após a "disrupção" das rotinas. Isto é, o desastre passa a ser remetido não aos efeitos e relações de poder criados e reiterados em decorrência da interação entre a ameaça natural e a organização social, mas sim a uma ação pontuada pelo

\footnotetext{
${ }^{2}$ O IBGE (2013) define o aglomerado subnormal como um conjunto constituído por cinquenta e uma ou mais unidades habitacionais dispostas, em geral, de forma desordenada e densa, caracterizadas por ausência de título de propriedade ou obtenção recente (dez anos ou menos) e ao menos uma das seguintes características: irregularidade das vias de circulação e do tamanho e forma dos lotes e/ou carência de serviços públicos essenciais (coleta de lixo, rede de esgoto, rede de água, energia elétrica e iluminação pública).

3 A aclividade/declividade moderada foi classificada entre $5 \%$ (2,9 graus) e $30 \%$ ( 16,7 graus) de inclinação. A aclividade/declividade acentuada como igual ou superior a $30 \%$ (16,7 graus) de inclinação (IBGE, 2013).
} 
fenômeno chuvoso que remete às práticas pontuais de prevenção que as pessoas adotaram quando informadas da ameaça pelos meteorologistas. Em outros termos, para alguns agentes dotados de capital científico e político, as mortes decorrem da não proteção das pessoas frente à fúria da natureza, da não compreensão delas perante o risco informado pelos peritos em seus boletins meteorológicos. As mortes e eventuais danos são em consequência da não adoção de uma proteção individual, de modo que as vítimas passam a ser culpabilizadas (SIENA; VALENCIO, 2005).

Mas essa construção simbólica em torno da definição do desastre como circunscrita ao evento natural obscurece as relações de poder emergidas como consequência da interação entre esse evento natural e a organização social. Dessa interação surgem novas figurações, as quais passam a ser ordenadas dentro de uma luta pelas classificações, criando e reafirmando posições no campo do desastre que se afirmam pela linguagem oral como também pela linguagem visual. Isto é, há linguagens visuais que estão presentes na produção simbólica do desastre que se somam às palavras na criação de determinadas realidades, reiterando as injustiças ambientais no contexto dos desastres.

\section{0 desastre como espetáculo: do consumo da imagem da desordem e da dor à produção do mecanismo problema-solução}

Uma das grandes obras de Walter Benjamin, A obra de arte na era de sua reprodutibilidade técnica, foi escrita em 1936 durante seu exílio em Paris. Ao escrevê-la, seu objetivo era criticar a apropriação e o uso político que os regimes totalitários fizeram de alguns conceitos tradicionais, como criatividade e gênio. A crítica que empreende revela que tais conceitos possuem, em sua essência, toda uma lógica política que demonstra que os modos de produção também são responsáveis pela produção da cultura. Nessa sua crítica, é clara sua postura de ser uma intervenção política socialista de forma a combater o regime fascista, intervenção esta que poderia advir por meio do uso político da arte, que também se desenvolveria no plano de uma luta simbólica pautada pela criação de novos conceitos que serviriam como uma nova forma de enunciar a realidade.

Para possibilitar o uso político da arte, era preciso demonstrar que ela pode ser produzida, inclusive, pela referência a novos conceitos, como 
o da reprodutibilidade técnica. Esse conceito relaciona o uso da técnica à produção da cultura, concebendo a arte como uma produção que se pode efetivar por meio da técnica, que não depende necessariamente da criatividade e genialidade. Assim, a possibilidade de reproduzir tecnicamente uma obra de arte engendraria sua refuncionalização, de modo a permitir que fosse desenvolvida uma função não de contemplação (culto), mas sim de exposição. A partir disso, o valor de culto (fundado no ritual), associado historicamente à esfera religiosa, passa a se fundar a partir de um valor de exposição (ligado à reprodutibilidade técnica) que, por sua vez, possibilita um maior acesso das pessoas à arte, democratizando o acesso das massas, fundando-se, assim, sob uma práxis política: “(...) com a reprodutibilidade técnica, a obra de arte se emancipa (...) destacando-se do ritual. A obra de arte reproduzida é cada vez mais a reprodução de uma obra de arte criada para ser reproduzida (...). Em vez de fundar-se no ritual, ela passa a fundar-se em outra práxis: a política” (BENJAMIM, p. 171-172).

Em outras palavras, se, "no interior dos grandes períodos históricos, a forma de percepção das coletividades humanas se transforma ao mesmo tempo que seu modo de existência" (Idem p. 169), essa transformação se desenvolve porque o modo de percepção do mundo é condicionado historicamente pelos meios técnicos que se possui, razão pela qual "a reprodutibilidade técnica da obra de arte modifica a relação da massa com a arte. Retrógrada diante de Picasso, ela se torna progressista diante de Chaplin” (Idem p. 187). É por meio da função social e política da arte democratizada que Benjamin deposita sua crença na possibilidade de uma renovação mundial, de uma mudança política que sedimentasse os regimes totalitários e ensejasse a implantação do socialismo.

Se, para Benjamin, a técnica adquire um valor positivo de libertação da sociedade, para Adorno (1986) o seu uso se dá a fim de dominá-la, de modo que o poder técnico será detido pelos que possuem os meios de produção. A técnica tem uma função econômica, implementa a padronização e a produção em série para cumprir essa função. Em outras palavras, se "a reprodutibilidade técnica da obra de arte modifica a relação da massa com a arte" (BENJAMIN, 1994, p. 187), isso se processa não como um potencial emancipatório, mas sim de escravização: "a dominação técnica progressiva se transforma em engodo das massas, isto é, em meio de tolher a sua consciência” (ADORNO, 1986, p. 99).

Isso porque, para Adorno, as formas de produção de cultura sob o sistema capitalista estão inseridas em um sistema organizado, que se constitui como 
uma indústria cultural - é regida administrativamente, detém capital e meios de produção -, e a técnica está a serviço desse projeto "de como e para quem produzir a cultura”. Desse modo, se Benjamin via o cinema como sendo responsável por uma função social de possibilitar ao homem uma nova forma de representar o mundo, para Adorno ele está inserido no sistema da indústria cultural e "reorienta as massas, não permite quase a evasão e impõe sem cessar os esquemas de seu comportamento" (Idem p. 98). Na ideologia que dissemina, "o conformismo substitui a consciência; jamais a ordem por ela transmitida é confrontada com o que ela pretende ser ou com os reais interesses dos homens" (Idem p. 97).

Se a reprodutibilidade técnica assumia, para Benjamin, a possibilidade de luta política e emancipação, a luta concorrencial travada no campo da produção simbólica do desastre não se desencadeia no sentido de revelar a fala dos dominados para um uso político deles próprios, mas de instituir o consumo de suas imagens pela disputa das imagens-mercadorias com maiores valores de troca, na luta concorrencial que os agentes dos meios de comunicação travam no campo, definindo o que é ordem e desordem.

Assim, as imagens fotográficas "e suas variantes, no filme e no vídeo, antecipam ou mesmo substituem a própria pessoa na reprodução das relações sociais" (MARTINS, 2008, p. 23), tais como as imagens de desastres que passam a ser veiculadas em tempo real. Embora pareçam reproduzir fidedignamente a realidade, são resultado de seleções, recortes e composições, pois os agentes do campo comunicacional estão em disputa pelo monopólio da visão sobre o que constitui a realidade, modulando uma seleção do tempo real. As imagens expressam uma relação de poder à medida que as relações entre os dominantes e os dominados se perpetuam como a produção simbólica do desastre, silenciando as formas de violência subsumidas nessas relações no campo do desastre. Um dos exemplos desse processo se refere à propagação das imagens dos saques ocorridos, em novembro de 2008, durante os eventos hidrometeorológicos ocorridos no Vale do Itajaí/SC, as quais podem se constituir como que dotadas de capital simbólico, veiculando conteúdos morais que visam associar a desordem pública como resultado da índole má, da ignorância do grupo envolvido referente às regras sociais da "civitas", e não como alternativa de sobrevivência imediata do grupo diante da ineficiência das instituições envolvidas nas ações de socorro e emergência na provisão de alimentos e de outros bens perdidos.

Nesse sentido, sobre as imagens pairam juízos de valor e uma luta classificatória que visa nomear os que estão em interação para endossar 
procedimentos que verticalizam a compreensão do mundo e a concepção de ordem: aos desviantes passa a corresponder como o Outro, as instituições que se veem "obrigadas" a restituir o controle total sobre o espaço, sem questionamento ou negociação. Aos que resistem a sair de suas casas, como "os ignorantes", os que pegam comidas dos supermercados como "os ladrões" (vide Figura 1), os que reclamam das instituições públicas, fica a pecha de "desordeiros", a quem, "apesar de tudo", o ente público preocupa-se em dar abrigo. Isto é, há uma concepção de poder propagada pelas imagens que está além do economicismo, pois a dimensão política da instrumentalização das imagens ocorre a partir de seleções e recortes, de visibilidades e invisibilidades que compõem a produção de determinada realidade.

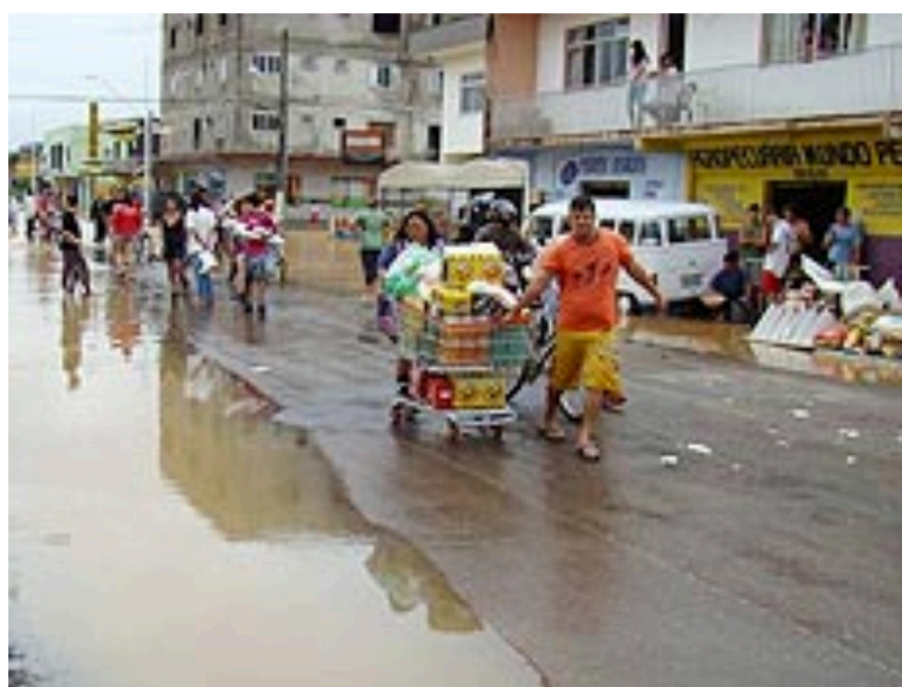

Heda Wenzel/Leitora

Figura 1: Fotógrafa da Folha Online registra 'saqueadores' na cidade de Itajaí/SC, no mês de novembro de 2008 (WENZEL, 2008).

Legenda: Em meio às águas baixando, observa-se a ênfase dada pela fotógrafa e jornalista da Folha Online no dia 27 de novembro a um homem e uma mulher que, juntos, carregavam, à luz do dia, num carrinho de supermercado, fardos de refrigerante (em maior quantidade) e de cerveja, sendo observados por outros moradores. Ao fundo da Figura, observa-se que havia um grupo de mulheres carregando sacolas plásticas de supermercado, mas com nenhum fardo de cerveja junto às mãos. Nesse sentido, as imagens passam a mediar relações entre pessoas e ensejam determinados julgamentos morais, lutas classificatórias em torno dos fenômenos de modo a produzir uma determinada realidade.

As imagens são "expressão de uma necessidade do imaginário, uma linguagem e um discurso visual [...] um discurso visual dotado de vida e 
legalidade próprias" (MARTINS, 2008, p. 30). Como tais, são sempre resultado de uma seletividade de focos que tende a hierarquizar o que é visto, ordena imaginariamente o irrelevante da vida cotidiana, criando desprezos visuais, de modo que a "definição da pessoa e das próprias relações sociais, na modernidade, tornou-se dependente de imagens e do enquadramento do visto no imaginado" (Idem p. 47). As imagens passam a ser um meio de exercer o poder e de fazê-lo funcionar, "produz coisas, induz ao prazer, forma saber, produz discurso" (FOUCAULT, 1984, p. 8). Não se pode desconsiderar que, embora esses mecanismos de poder não estejam restritos à esfera do Estado, a ele se articulam de maneiras variadas e são indispensáveis à sua sustentação e atuação eficaz (FOUCAULT, 1984). Isto é, há uma instrumentalização política das imagens que, selecionadas, tendem a hierarquizar o que é visto, definindo as pessoas e suas relações sociais. Os agentes dos meios de comunicação produzem discursos e formam saberes a partir das imagens, produzindo simbolicamente a ideia de que o Estado está atuando de forma eficaz no desastre, e as eventuais falhas e desordens são delegadas aos agentes que detêm menor capital no campo, ou seja, os pobres.

No caso dos saques ocorridos, no final de novembro de 2008, em Itajaí/ $\mathrm{SC}$, os meios de comunicação difundiram reportagens nas quais a associação de imagens e relatos visou criar uma representação de que a desordem na cidade não era em decorrência da ineficiência das instituições de atuação em desastres e emergências, mas em razão da ação de um grande número de "saqueadores", que se aproveitariam das fortes chuvas e da situação de emergência para roubar comida, bebida, material de limpeza, geladeira e utensílios domésticos:

A Polícia Civil de Santa Catarina prendeu nesta quarta-feira 20 pessoas suspeitas de saquearem um supermercado no município de Itajaí. 'Os invasores se aproveitaram das fortes chuvas e da situação de emergência na cidade, em função das enchentes, para invadir o estabelecimento de onde levaram diversos produtos', informou a polícia em comunicado divulgado ontem. De acordo com a corporação, os suspeitos carregavam comida, bebida, material de limpeza e higiene, além de dois aparelhos de TV de plasma, uma geladeira e utensílios domésticos. (WENZEL, 2008).

Lindell, Prater e Perry (2006), ao desenvolverem estudos e pesquisas sobre alguns desastres nos Estados Unidos que tiveram relação com fenômenos naturais (furacões, tornados etc.), chegaram à conclusão de que existem alguns mitos em relação aos desastres que obscurecem o que 
realmente acontece neles, sendo a prática de saques um desses exemplos. Esses seriam fenômenos bem restritos e não revelariam o que acontece, de forma abrangente, num desastre. Entretanto, se operarmos com a lógica de que a exceção ganha visibilidade pela trama midiática como sendo a regra de comportamento coletivo, podemos depreender que se tem configurado um interesse em classificar os atingidos de modo a desprestigiar suas ações no espaço público como sendo legítimas, mesmo em meio a uma configuração espacial caótica e desigual.

Thompson (1998), ao pesquisar os motins e os saques nos períodos de fome e escassez ao longo do século XVIII, ressaltou que esses eram desencadeados não como resultado mecânico de um estímulo econômico do aumento do preço do alimento, mas permeados por complexidades da motivação, comportamento e função, longe de serem compulsivas. Isto é, para o autor, haveria em quase toda ação popular, do século XVIII, uma noção legitimadora, na qual homens e mulheres "da multidão estavam imbuídos da crença de que estavam defendendo direitos ou costumes tradicionais: e de que, em geral, tinham o apoio do consenso mais amplo da comunidade" (THOMPSON, 1998, p. 152).

Esse autor afirma que essa noção de economia moral denotava algumas concepções definidas do que constituía o bem-estar comum para o povo, fundamentadas na tradição paternalista das autoridades. Os motins funcionavam, muitas vezes, como formas de pressão, "como um sinal para os ricos de que era preciso colocar em bom estado os mecanismos de assistência e caridade da paróquia - cereais e pão subsidiados para os pobres" (Idem p. 190).

Se pensarmos em alguns casos de saques ocorridos em contextos de desastres no Brasil, talvez eles possam ser compreendidos como um sinal de que os mecanismos de assistência precisam ser acionados; mas revelam, antes de tudo, que há uma descrença de que esses vão ser desencadeados pelos agentes do Estado em atuação nos cenários de emergências e desastres, descrença que é fruto de históricas produções de injustiça social e ambiental. Como exemplo desse processo, em 2 de junho de 2005, em vídeo produzido pela Prefeitura Municipal de Jaboatão dos Guararapes/PE, registraram-se as chuvas ocorridas no município, reportando em algumas imagens um grupo de jovens nadando em meio à enchente na região do Jaboatão Centro tentando obter alguns colchões novos de uma loja inundada, num conjunto de imagens que buscavam produzir simbolicamente o imaginário da desordem, aproveitando-se desse "mito" para conferir às pessoas à culpabilização por 
esta, tirando o foco das razões que materializaram tanto aquela situação da enchente como, por exemplo, as más condições de drenagem urbana quanto, principalmente, as causas para pessoas precisarem buscar itens de primeira necessidade em meio à destruição o que, sem dúvida, deve-se à pobreza estrutural.

No caso do desastre de Jaboatão, mais de quatro mil pessoas perderam suas casas e tiveram de ir para abrigos temporários organizados em escolas públicas. Passados dois anos da ocorrência das enchentes, ainda havia aproximadamente mil pessoas em abrigos temporários aguardando a reconstrução de suas casas, isso porque o processo de reconstrução foi atravancado por questões políticas (VALENCIO; MARCHEZINI; SIENA, 2009). No caso dos saques ocorridos no município de Itajaí/SC, os meios de comunicação os descreveram como situações de festa (reveillon) em que caberia correr "riscos" ("com a água na altura do pescoço") para levar tudo o que estivesse ao alcance das mãos, representando a partir de imagens um caráter racial desses saqueadores, no caso homens negros (vide Figura 2):

Com a água na altura do pescoço, os saqueadores levavam tudo o que estava ao alcance das mãos. Uma mulher grita a um conhecido: "Tu não queres um chester? Tem um boiando ali". Uns juntavam chinelos, outros recolhiam bebidas: água, refrigerantes, cerveja e até champanhe. "É para o Réveillon", dizia um deles sem culpa. Cabos de vassoura eram feitos de suporte para carregar as "compras" do mês nos ombros. No interior da loja, numa escuridão em que quase nada se via, famílias garimpavam os produtos largados no chão e escalavam as prateleiras.

Do lado de fora, bicicletas, carroças, carrinhos de mão, carros velhos e de luxo e até caminhões eram carregados com os produtos. Um deficiente físico pedalava um triciclo com uma perna só e, junto com bebidas, carregava uma muleta. (GALVÃO; LOPES JUNIOR; IZIDORO, 2008). 


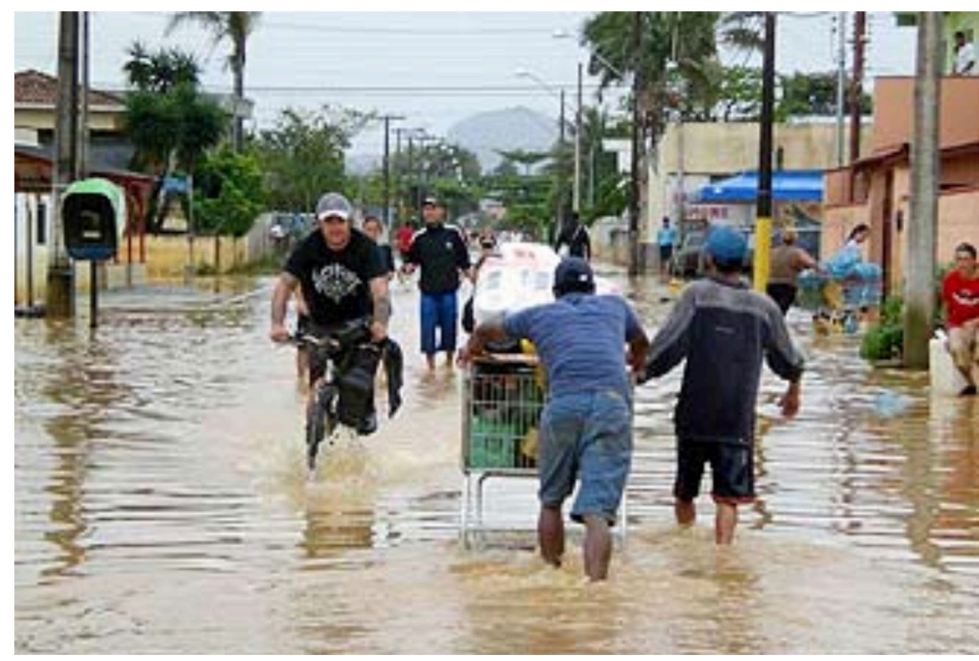

Heda Wenzel/Leitora

Figura 2: Fotógrafa da Folha Online registra "saqueadores" negros na cidade de Itajaí/SC, no mês de novembro de 2008 (GALVÃO; JÚNIOR; IZIDORO, 2008).

Legenda: Em meio às águas baixando, observa-se a ênfase dada pela fotógrafa e jornalista da Folha Online no dia 27 de novembro a um grupo de homens negros que, juntos, carregavam, à luz do dia, num carrinho de supermercado, diversos produtos, sendo observados por outros moradores. Martins (2008, p. 74) afirma que o "flagrante de um instantâneo fotográfico pode ocultar muita coisa, pode reduzir a realidade social à brevidade de um fragmento", ou seja, a realidade presente neste fragmento visa produzir uma realidade, produz discursos porque estão imbuídas de relações de poder, mas também obscurecem relações políticas aí imbricadas que podem revelar a descrença no poder público no tocante à provisão de alimentos, por exemplo.

Os saques, os motins eram, para Thompson (1998), formas de ação coletiva, mas não se constituíam como as únicas, pois jejuns, sacrifícios e petições em massa às autoridades também eram exercidos. Essas ações não eram uma "resposta natural ou óbvia à fome, mas um padrão sofisticado de comportamento coletivo, uma alternativa coletiva a estratégias individualistas e familiares de sobrevivência" (THOMPSON, 1998, p. 208), fato este verificado no caso dos saques de Itajaí/SC, que envolviam um grande número de pessoas (Figura 3), implicando "um padrão de protesto social que deriva de um consenso a respeito da economia moral do bem-estar público em tempos de escassez" (Idem p. 193). Falar em economia moral implicaria, segundo o autor, considerar as "profundas emoções despertadas pelo desabastecimento, as reivindicações populares junto às autoridades nessas crises" (Idem p. 257), sendo a manifestação uma forma de compartilhamento de assuntos comuns a todos, uma vivência do mundo constituído entre os homens, uma ação 
que busca a efetivação da condição de pluralidade. Segundo Arendt (2005, p. 192), "na ação e no discurso, os homens mostram quem são (...) apresentamse ao mundo humano", circundados pela teia de atos e palavras de outros homens, e o poder passa a existir entre eles quando agem juntos para revelar realidades que são invisibilizadas, tal como a inexistência de ações de socorro e provimento de alimentos por parte do Estado.

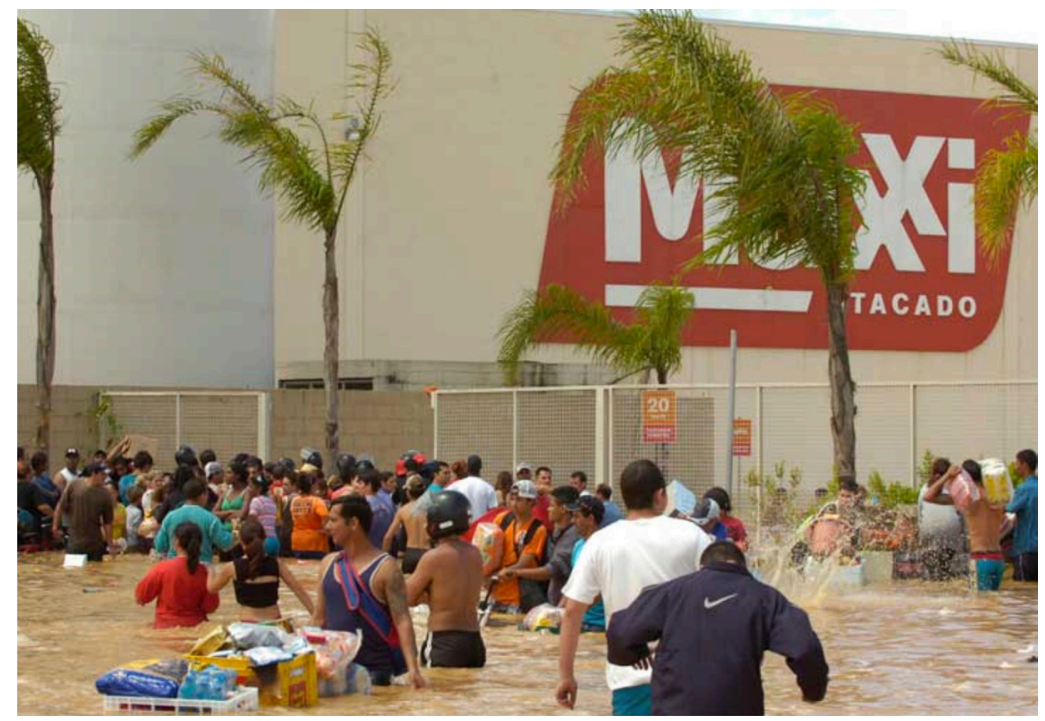

Figura 3 - Ação coletiva em supermercado de Itajaí/SC (Fonte:http://www.clicrbs.com.br/rbs/ image/5497419.jpg. Acesso em: 02 fev. 2009).

Ao analisar, no século XVIII, como as autoridades reagiam aos saques e motins, Thompson afirma que elas procuravam demonstrar "para os pobres de que (...) agiam vigilantemente para defender os seus interesses" (THOMPSON, 1998, p. 60). A produção desse efeito simbólico, no caso do desastre do Vale do Itajaí/SC, deu-se a partir da difusão de reportagens e imagens das doações de alimentos, roupas e doações em dinheiro vindas de diversas partes do Brasil, constituindo-se como a produção do mecanismo solução-problema (cf. DOMBROWSKY, 1998), isto é, em meio ao problema advindo em razão do "excesso de chuvas", as soluções estavam sendo tomadas no provimento dos alimentos, roupas, abrigo, atendimento médico etc., ou seja, diante da ignorância, incapacidade, impotência, enfim, inferioridade constatada dos atingidos pelas enchentes, contrapunham-se a altivez e compaixão dos doadores e heroísmo dos agentes do Estado. Aos poucos, 
tudo estava voltando à "normalidade", devido à essa composição de sujeitos na cena.

Entretanto, nessa produção simbólica do mecanismo problema-solução - como se a vida pudesse voltar ao normal para muitos dos que perderam familiares - obscureceram-se muitas relações de poder imbricadas na definição das razões do desastre, como, por exemplo, a falha logística das esferas municipal, estadual e federal no transporte de alimentos que tardaram a chegar enquanto muitos passavam fome; os que ficaram dias isolados e sobreviveram graças ao apoio coletivo, como as comunidades do Morro do Baú, cujos salvamentos realizados pelos helicópteros das Forças Armadas ressaltaram o heroísmo destes em detrimento das estratégias comunitárias de salvamento diante da ineficiência do Estado; as tentativas de suicídio, assédio sexual e tráfico de drogas em alguns abrigos temporários em razão da inexistência de um plano para organização e administração de abrigos temporários (MARCHEZINI, 2014a). As imagens definiram no imaginário nacional a representação de um desastre que ocorreu, sedimentado a partir da produção simbólica da normalidade, isto é, da superação do desastre pela atuação da eficiência do Estado e do apoio nacional no provimento de doações. Mas a definição da temporalidade do desastre está alicerçada nas experiências daqueles que estão vivenciando-o, não necessariamente implicando que todos tenham superado ou irão superá-los, pois os desastres são classificados a partir dos pontos de vista dos agentes, embora a representação hegemônica do que é o desastre esteja longe de considerar as perdas materiais e imateriais dos afetados, classificando-os como desastres naturais, subestimando a importância destes para a vida social, incorrendo numa violência simbólica que procura dar a forma produzida publicamente de que o sofrimento social é consequência de algo natural e não de algo produzido a partir das relações sociais.

\section{Para concluir}

Se a forma de percepção das coletividades humanas é condicionada historicamente pelos meios técnicos que se possui, transformando-se ao mesmo tempo que seu modo de existência (cf. BENJAMIN, 1994), a centralidade que as imagens adquirem como uma linguagem e um discurso visual demonstra que passam a ser significadas como dotadas de vida e legalidades próprias (cf. MARTINS, 2008), como existência real e não 
como resultado de seleção e produção simbólica de uma dada realidade. A instrumentalização política das imagens dos saques ocorridos durante as enchentes do Vale do Itajaí/SC revela como o conteúdo do que vem a ser constituído como desastre é oriundo de uma seletividade de focos que tende a hierarquizar o que é visto, criando desprezos visuais, enunciando o que se constitui como ordem e desordem.

Nesse processo de produção simbólica do desastre, a própria noção de tempo real é resultado de uma seleção, composição, articulação de imagens e depoimentos, demonstrando os jogos de poder para enunciação da visão do que é realidade. Nessa disputa, os agentes dos meios de comunicação produzem discursos e formam saberes a partir das imagens, produzindo simbolicamente a ideia de que o Estado está atuando de forma eficaz no desastre, e as eventuais falhas e desordens são delegadas aos agentes que detêm menor capital no campo, ou seja, os pobres.

Há modos de se articularem imagens, atores e testemunhos, estabelecendo um enredo para a construção social do desastre, definindo temas e pautas que terão visibilidade, que serão vendidas aos telespectadores. As imagens ao vivo de cenários de desastres também se compõem de edições, composições, seleções e recortes. Nem todos os desastres viram notícia, nem todos têm a mesma visibilidade, tampouco o mesmo tempo de cobertura televisiva. Os que são produzidos simbolicamente como "desastres naturais" têm seu tempo de vigência definido pela audiência, pela disputa com outras pautas, pela política e pelo mercado que permeia o campo comunicacional etc. Quando um desastre vira pauta, ele se torna uma realidade cujo roteiro é caracterizado por discursos que evocam temas centrais (DYNES, RODRÍGUEZ, 2007): imagens da destruição e dos danos permitem aos telespectadores usar sua própria imaginação para projetar os significados dessas perdas; os números das mortes, dos desabrigados, dos desalojados e dos afetados são atualizados recorrentemente para demonstrar a constante busca pela amplitude da tragédia; repórteres reiteradamente perguntam sobre as ações de resgate, de ajuda e de assistência, além de veicularem histórias sobre os problemas de segurança pública nesse contexto, como saques, pessoas que resistem a sair das áreas de risco etc. De uma hora para outra, o desastre sai de pauta, tornando-se uma pauta invisível. E os atingidos continuam a viver o desastre nos campos de desabrigados, lançados a uma catástrofe social que não é vivida como drama público. 


\section{Referências}

ACSELRAD, Henri.

(2002). Justiça ambiental e construção social do risco. In: Anais do XIII Encontro da Associação Brasileira de Estudos Populacionais. Caxambu: ABEP. Disponível em: <http://www.abep. nepo.unicamp.br/docs/anais/pdf/2002/ GT_MA_ST5_Acselrad_texto.pdf $>$. Acesso em 01 julho de 2008.

(2006a). Vulnerabilidade Ambiental, processos e relações. Comunicação oral apresentada no II Encontro Nacional de Produtores e Usuários de Informações Sociais, Econômicas e Territoriais. FIBGE, Rio de Janeiro.

(2006b). As cidades e as apropriações sociais das mudanças climáticas. Cadernos IPPUR, Rio de Janeiro, v. 20, n. 1, p. 77-106.

(2010). Ambientalização das lutas sociais - 0 caso do movimento por justiça ambiental. Estudos Avançados, 24, (68), p.103-119.

ACSELRAD, Henri; MELLO, Cecília Campello do Amaral; BEZERRA, Gustavo Antônio das Neves. (2008). O que é justiça ambiental. Rio de Janeiro: Garamond.

ADORNO, Theodor. W.

(1986). A Indústria Cultural. In: COHN, Gabriel. Theodor W. Adorno: sociologia. São Paulo: Ática, p. 92-99.

\section{AGÊNCIA FOLHA}

(2007). Governo libera $R \$ 135$ mi para AM após chuva. Jornal Folha de S.Paulo. São Paulo, quarta-feira, 18 de abril de 2007. Disponível em: <http://www1.folha.uol.com.br/fsp/ cotidian/ff1804200724.htm>. Acesso em 08 janeiro de 2009.

ARENDT, Hannah

(2005). A condição humana. Rio de Janeiro: Forense Universitária.

ALVES, Humberto Prates da Fonseca; TORRES, Haroldo da Gama.

(2006). Vulnerabilidade socioambiental na cidade de São Paulo: uma análise de famílias e domicílios em situação de pobreza e risco ambiental. São Paulo em Perspectiva, 20 (1 jan/mar), 44-60. São Paulo: Fundação Seade.

BECK, Ulrich.

(1997). A Reinvenção da Política: rumo a uma teoria da modernização reflexiva. In: BECK, U.; GIDDENS, A.; LASH, S (Orgs). Modernização Reflexiva: política, tradição e estética na ordem social moderna. São Paulo: Editora da Universidade Estadual Paulista. p.11-71.

BENJAMIM, Walter.

(1994). A obra de arte na era de sua reprodutibilidade técnica. In: Walter Benjamin; Obras escolhidas. 5 ed. São Paulo: Brasiliense, v.1. p.165-196.

BOURDIEU, Pierre.

(1988). Lições de aula. São Paulo: Ática. Série Temas. Vol. 8. p.3-63.

(1996). Razões Práticas: sobre a teoria da ação. Campinas: Papirus Editora.

(2004). O PoderSimbólico.7.. ed. Rio de Janeiro: Bertrand Brasil.

(2006) A produção da crença: contribuição para uma economia dos bens simbólicos. Porto Alegre: Zouk.

BOURDIEU, Pierre; CHAMBOREDON, JeanClaude; PASSERON, Jean-Claude.

(2007). 0 ofício de sociólogo: metodologia de pesquisa na sociologia. Petrópolis: Vozes.

CARM0, Roberto do

(2014). Urbanização e desastres: desafios para a segurança humana no Brasil. In: Roberto do Carmo; Norma Felicidade Lopes da Silva Valêncio (Orgs.); Segurança Humana no Contexto dos Desastres. São Carlos: Rima Editora. p.1-14.

DYNES, Russel; RODRÍGUEZ, Havidán.

(2007). Finding and framing Katrina: the social construction of Disaster. In: David Brunsma; David Overfelt; Steven Picou (Eds); The Sociology of Katrina: Perspectivesof a Modern Catastrophe. Lanham / Boulder / New York / 
Toronto / Plymouth: Rowman and Littlefield Publishers. p 23-33.

DOMBROWSKY, Wolf. Rüdiger.

(1998). "Again and again: is a disaster we call a 'disaster'?". In: Enrico Quarantelli (Org.); What is a disaster? Perspectives on the question. London and New York: Routledge. p.19-30.

FOUCAULT, Paul-Michel.

(1984). Microfísica do Poder. Rio de Janeiro: Graal.

GALVÃO, Vinícius Queiroz; LOPES JUNIOR, Moacyr; IZIDORO, Alencar.

(2008). Em loja alagada de Itajaí (SC), saqueadores levam de tudo. Folha Online. 27 de novembro de 2008. Disponível em: <http://www1.folha.uol.com.br/folha/ cotidiano/ult95u472219.shtml>. Acesso em 02 de janeiro de 2009.

GIDDENS, Anthony.

(1991). As consequências da modernidade. São Paulo: Unesp.

(2009). The politics of climate change. Cambridge: Polity Press.

INSTITUTO BRASILEIRO DE GEOGRAFIA E ESTATÍSTICA.

(2013). Censo Demográfico 2010: Aglomerados subnormais, informações territoriais. Rio de Janeiro: IBGE.

LINDELL, Michael Keith; PRATER, Carla Sue; PERRY, Ronald William.

(2006). Emergency Management Principles and Practices. Washington DC:John Wiley.

MARCHEZINI, Victor.

(2014a). Campos de desabrigados - a continuidade do desastre. São Carlos: Rima.

(2014b). "La producción silenciada de los 'desastres naturales' en catástrofes sociales". Revista Mexicana de Sociologia, v.76, n.2, p.253-285.

MARTINS, José de Souza.

(2008). Sociologia da Fotografia e da Imagem.

São Paulo: Contexto.
NUNES, Luci Hidalgo.

(2008). Mudanças Climáticas: impactos físicos e socioeconômicos. Plenarium, v.5, p.66-82.

(2009). “Mudanças climáticas, extremos atmosféricos e padrões de risco a desastres hidrometeorológicos". In: Daniel Joseph Hogan; Eduardo Marandola Jr. (Orgs.); População e mudança climática: dimensões humanas das mudanças ambientais globais. Campinas: NEPO/Unicamp; Brasília: UNFPA.

PAINEL INTERGOVERNAMENTAL SOBRE MUDANÇA DO CLIMA (IPCC).

(2007). Mudança do Clima 2007: Impactos, Adaptação e Vulnerabilidade. Bruxelas: 0MM/ PNUMA. Disponível em:< http://www.mct. gov.br/upd_blob/0015/15131.pdf>. Acesso em 24 de julho de 2008.

SIENA, Mariana; VALENCI0, Norma Felicidade Lopes da Silva.

(2005). Danos imateriais relacionados às chuvas: culpabilizando a vítima. Revista EcoTerra Brasil: temas ambientais. Disponível em: <http:// www.ecoterrabrasil.com.br>. Acesso em 02 de junho de 2005.

THOMPSON, Edward Palmer.

(1998). Costumes em comum. São Paulo: Companhia das Letras.

TV CANAL 13.

(2008). Chuvas atípicas causam transtornos. Teresina, 20 julho de 2008. Disponível em: http://www.tvcanal13.com.br/noticias/ chuvas-atipicas-causam-transtornos-29759. asp. Acesso em 09 janeiro de 2009.

VALENCIO, Norma Felicidade Lopes da Silva. (2012). Para além do "dia do desastre" - o caso brasileiro. Curitiba: Editora Appris.

VALENCIO, Norma Felicidade Lopes da Silva; MARCHEZINI, Victor; SIENA, Mariana; CRISTOFANI, Guilherme.

(2005). Chuvas no Brasil: representações e práticas sociais. Revista Política e Sociedade, Florianópolis, v. 4, n. 7, p. 163-183. 
VALENCIO, Norma Felicidade Lopes da Silva; MARCHEZINI, Victor; SIENA, Mariana.

(2009). Desastre e indiferença social: o Estado perante os desabrigados. Antropolítica (UFF), v.23, p.223-254.

VALENCIO, Norma Felicidade Lopes da Silva; SIENA, Mariana; MARCHEZINI, Victor.

(2011). Abandonados nos desastres: uma análise sociológica de dimensões objetivas e simbólicas de afetação de grupos sociais desabrigados e desalojados. Brasília: Conselho Federal de Psicologia.
WENZEL, Heda.

(2008). Saques a lojas preocupam comerciantes em Itajaí (SC). Folha Online. 27 novembro de 2008. Disponivel em: <http://www1.folha. uol.com.br/folha/cotidiano/ult95u472163. shtml>. Acesso em 03 de janeiro de 2009.

\section{Recebido em}

janeiro de 2014

Aprovado em

junho de 2014 